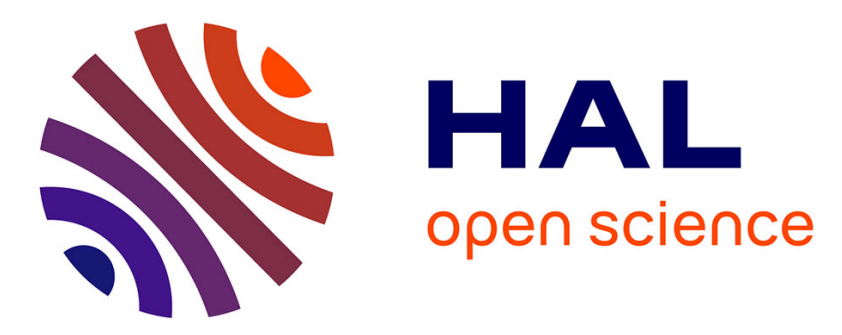

\title{
Integration of dynamic behaviour variations in the stability lobes method: 3D lobes construction and application to thin-walled structure milling
}

Vincent Thévenot, Lionel Arnaud, Gilles Dessein, Gilles Cazenave-Larroche

\section{- To cite this version:}

Vincent Thévenot, Lionel Arnaud, Gilles Dessein, Gilles Cazenave-Larroche. Integration of dynamic behaviour variations in the stability lobes method: 3D lobes construction and application to thinwalled structure milling. International Journal of Advanced Manufacturing Technology, 2006, vol. 27, pp. 638-644. 10.1007/s00170-004-2241-1 . hal-00800292

\section{HAL Id: hal-00800292 https://hal.science/hal-00800292}

Submitted on 13 Mar 2013

HAL is a multi-disciplinary open access archive for the deposit and dissemination of scientific research documents, whether they are published or not. The documents may come from teaching and research institutions in France or abroad, or from public or private research centers.
L'archive ouverte pluridisciplinaire HAL, est destinée au dépôt et à la diffusion de documents scientifiques de niveau recherche, publiés ou non, émanant des établissements d'enseignement et de recherche français ou étrangers, des laboratoires publics ou privés. 


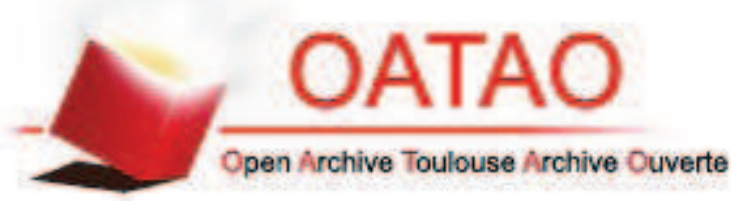

\section{Open Archive TOULOUSE Archive Ouverte (OATAO)}

OATAO is an open access repository that collects the work of Toulouse researchers and makes it freely available over the web where possible.

This is an author-deposited version published in : http://oatao.univ-toulouse.fr/ Eprints ID : 6388

To link to this article : DOI: $10.1007 / \mathrm{s} 00170-004-2241-1$

URL : http://dx.doi.org/10.1007/s00170-004-2241-1

To cite this version : Thévenot, Vincent and Arnaud, Lionel and Dessein, Gilles and Cazenave-Larroche, Gilles Integration of dynamic behaviour variations in the stability lobes method: $3 D$ lobes construction and application to thin-walled structure milling. (2006) The International Journal of Advanced Manufacturing Technology, vol. 27 ( ${ }^{\circ}$ 7-8). pp. 638-644. ISSN 0268-3768

Any correspondence concerning this service should be sent to the repository administrator: staff-oatao@,listes.diff.inp-toulouse.fr 


\section{Vincent Thevenot • Lionel Arnaud • Gilles Dessein • Gilles Cazenave-Larroche Integration of dynamic behaviour variations in the stability lobes method: 3D lobes construction and application to thin-walled structure milling}

\begin{abstract}
Vibratory problems occurring during peripheral milling of thin-walled structures affect the quality of the finished part and, to a lesser extent, the tool life and the spindle life. Therefore, it is necessary to be able to limit these problems with a suitable choice of cutting conditions. The stability lobes theory makes it possible to choose the appropriate cutting conditions according to the dynamical behaviour of the tool or the part. We introduce the dynamical behaviour variation of the part with respect to the tool position in order to determine optimal cutting conditions during the machining process. This generalization of the classical lobes diagram leads us to a 3D lobes diagram construction. These computed results are compared with real experiments of down-milling of thin-walled structures.
\end{abstract}

Keywords 3D stability lobes - Dynamic behaviour - Peripheral milling · Thin walled structures ·

\section{Notation}

$\alpha_{y y} \quad$ Directional dynamic milling coefficient in the $y$ direction

$\alpha_{i}(t) \quad$ Weight function of the considered mode

$\phi_{\text {ex }} \quad$ Exit angle

$\phi_{\text {st }} \quad$ Start angle

$\underline{\Phi}_{i}(\underline{x}) \quad$ Natural displacement of the considered mode

$\xi \quad$ Damping ratio

$\xi_{i} \quad$ Modal damping ratio of the considered mode

$\omega_{c} \quad$ Chatter pulsation

$\omega_{0} \quad$ Natural pulsation

V. Thevenot ( $\cdot$ G G. Cazenave-Larroche

Turbomeca,

47 avenue Szydlowski, 64511 Bordes Cedex, France

E-mail: vincent.thevenot@enit.fr

Tel.: +33-5-62442773

Fax: +33-5-62442708

L. Arnaud · G. Dessein

Laboratoire Génie de Production,

École Nationale d'Ingénieurs de Tarbes,

47 Avenue d'Azereix, BP 1629, 65016 Tarbes Cedex, France

\author{
$A_{e} \quad$ Radial depth of cut \\ $A_{p} \quad$ Axial depth of cut \\ $\underline{F}_{c} \quad$ Cutting force \\ $F_{r} \quad$ Radial force \\ $F_{t} \quad$ Tangential force \\ $G_{y}\left(i \omega_{c}\right)$ Transfer function of the machining system in the $y$ di- \\ rection \\ $k \quad$ Stiffness \\ $k_{i} \quad$ Modal stiffness of considered mode \\ $K_{r} \quad$ Radial milling force coefficient \\ $K_{t} \quad$ Tangential milling force coefficient \\ $m$ Whole number of full vibration cycles between pas- \\ sages of two teeth \\ $m_{i} \quad$ Modal mass of the considered mode \\ $M \quad$ Application point of the cutting force \\ $M_{0} \quad$ Normalization point of the considered mode \\ $n \quad$ Number of normal modes under consideration \\ $N \quad$ Spindle speed \\ $\underline{u}(\underline{x}, t)$ Displacement field of the workpiece considered as de- \\ formable \\ $U(t) \quad$ Displacement of the workpiece considered as a rigid \\ body \\ $z \quad$ Number of teeth
}

\section{Introduction}

During some machining operations, vibrations may occur between the part and the tool. This is particularly true in the case of milling when long tools with small diameters are used, or in peripheral milling of thin-walled structures. This phenomenon generates dimensional and geometrical inaccuracies and a poor surface finish (Fig. 1). A reduction of tool life and spindle life is also observed. Therefore, it is necessary to be able to understand the phenomenon, and to control it. Research into machine tool chatter vibrations go back to the 1950s with Tobias [1], Tlusty [2] and Merrit [3], who explained the regenerative chatter vibrations in orthogonal cutting and developed the stability lobes theory. This theory makes it possible, for a given spindle speed, to predict the 


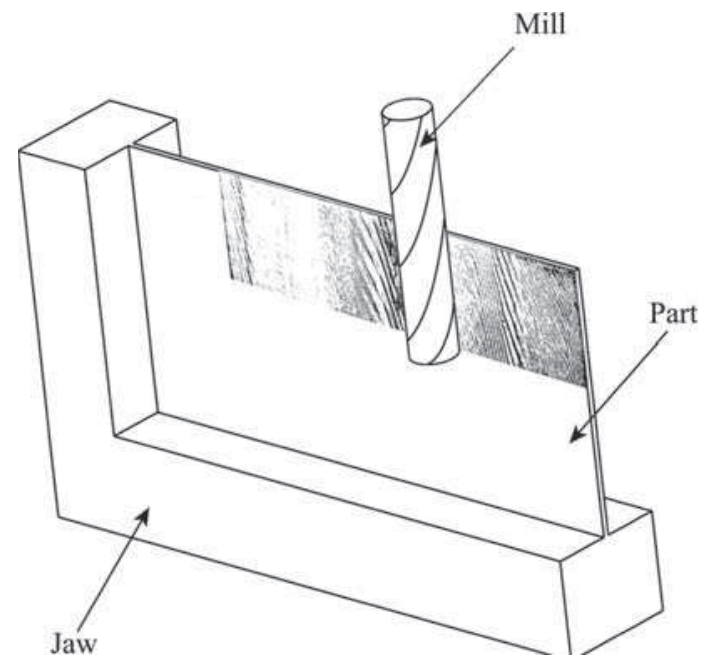

Fig. 1. Vibratory problems encountered in peripheral milling

engaged length of the cutting edge from which the vibrations will appear. This first model is particularly well-adapted to the tool chatter vibrations in turning, where the direction of the cutting force, chip thickness and dynamic parameters do not change with time. Orthogonal milling stability analysis (with a tool without a helix angle) appeared at the end of the 1960s [4, 5], and is used to study the vibrations of the tool. In the middle of the 1990s, Altintas [6] presented an analytical form of the stability lobes theory for milling. This theory can be applied to the study of tool vibrations, because its dynamic characteristics do not change with time. On the other hand, when a thin-walled structure is machined, one realizes that the dynamic behaviour of the tool-workpiece system depends on the tool position in the workpiece $[7,8]$. We will show in this article how to integrate the behaviour variations of the workpiece during machining.

\section{Stability lobes theory}

This study is mainly based on the work of Altintas and Budak [6, $9,10]$. Here, we only give the equations that allow us to trace the lobes.

The stability lobes theory is based on a regenerative chatter model. It aims to predict the oscillations due to tooth $n+1$ compared to tooth $n$ (Fig. 2).

\subsection{Initial assumptions}

- The workpiece is mobile compared to the tool, which is much more rigid than the workpiece.

- The workpiece can be considered as a rigid body in the machined zone.

- The material removal is neglected.

- The workpiece moves along the $y$ direction like a rigid body in the machined zone, according to the following equation:

$$
\ddot{U}+2 \xi \omega_{0} \dot{U}+\omega_{0}^{2} U=\left(\left(\underline{F}_{c} \cdot \underline{y}\right) \omega_{0}^{2}\right) / k
$$

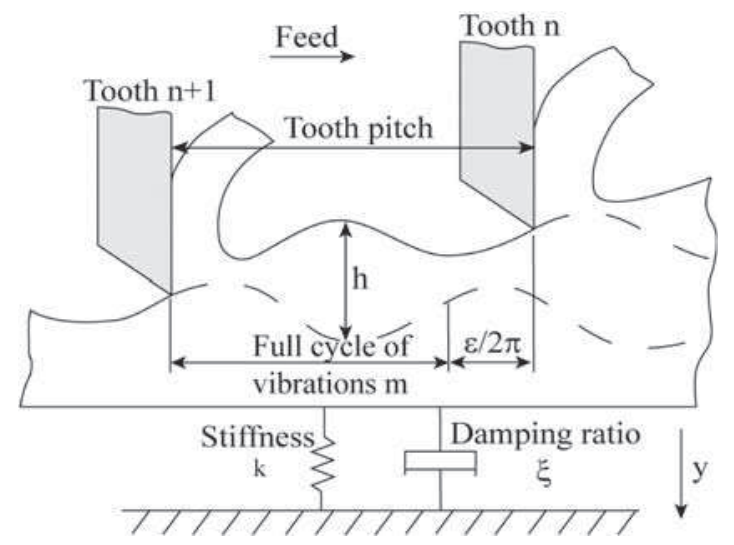

Fig. 2. Regenerative chatter model with one degree of freedom

- We use a linear cutting law of the type $F_{t}=K_{t} A_{p} A_{e}$ and $F_{r}=K_{r} F_{t}$, where $F_{t}$ and $F_{r}$ are, respectively, the tangential and radial cutting force, $K_{t}$ and $K_{r}$ the tangential and radial milling force coefficients, and $A_{p}$ and $A_{e}$ are the axial and radial depth of cut. We will avoid the cases where $A_{e} \ll f_{z}$, the feed per tooth, for which the linear cutting law is not very accurate [7]. It is the most difficult assumption to satisfy, considering the relatively small real radial depth of cut.

These assumptions are the simplest possible; our aim is to show how to construct the $3 \mathrm{D}$ lobes. This construction is applicable to more sophisticated models (non-linear cutting laws, multi degree of freedom, time domain simulations, etc.).

\subsection{Calculation of the critical axial depth of cut according to the chatter frequency}

Here, we express the critical axial depth of cut, $A_{\text {plim }}$, for one mode, with respect to the chatter frequency $\omega_{c}$ (vibration frequency of the workpiece). We use an orthogonal cutting model, although the lobe shape is not exactly the same with an oblique cutting model. But given the measurement inaccuracy for certain parameters, we prefer to use an orthogonal cutting model, which is easier to implement, and can be readjusted with tests. The displacement is considered along the $y$ direction, and we study the down-milling mode.

$A_{\text {plim }}=\frac{1}{\left(\frac{z}{2 \pi}\right) \alpha_{y y} K_{t} \Re \mathrm{Re}\left[G_{y}\left(i \omega_{c}\right)\right]}$

where $z$ is the number of teeth on the cutter.

$\alpha_{y y}$ is the directional dynamic milling coefficient in $y$ direction and is given by:

$\alpha_{y y}=\frac{1}{2}\left[-\cos (2 \theta)-2 K_{r} \theta-K_{r} \sin (2 \theta)\right]_{\phi_{\mathrm{st}}}^{\phi_{\mathrm{ex}}}$

where $\theta$ is the engagement angle of the tool, $\phi_{\text {ex }}$ is the exit angle of the tool and $\phi_{\mathrm{st}}$ is the start angle of the tool (Fig. 3).

$\mathfrak{R e}\left[G_{y}\left(i \omega_{c}\right)\right]$ is the real part of the structural transfer function of a system with one degree of freedom:

$\mathfrak{R e}\left[G_{y}\left(i \omega_{c}\right)\right]=\frac{1}{k}\left[\frac{1-d^{2}}{\left(1-d^{2}\right)^{2}+4 \xi^{2} d^{2}}\right]$ 
where $d=\omega_{c} / \omega_{0}, \omega_{0}$ is the natural pulsation, $k$ is the stiffness and $\xi$ is the damping ratio.

Thus, we obtain the graph represented in Fig. 4.

\subsection{Calculation of the spindle speed according}

to the chatter frequency

Here, we seek to express the spindle speed $N$ according to the chatter frequency $\omega_{c}$.

In Fig. 2, we note that there exists, between the passage of two teeth, $m$ full vibration cycles, and a fraction $\varepsilon /(2 \pi)$ of a cycle. When we express this phase angle according to the chatter frequency and the tooth frequency, we obtain the following expression:

$N=\frac{60 \omega_{c}}{z\left[2 m \pi+2 \pi-2 \arctan \left[\frac{d^{2}-1}{2 \xi d}\right]\right]}$

Equation 5 allows us to plot the curves (Fig. 5), where for $m$ fixed, we obtain the spindle speed corresponding to a chatter frequency with the same parameters as Fig. 4.

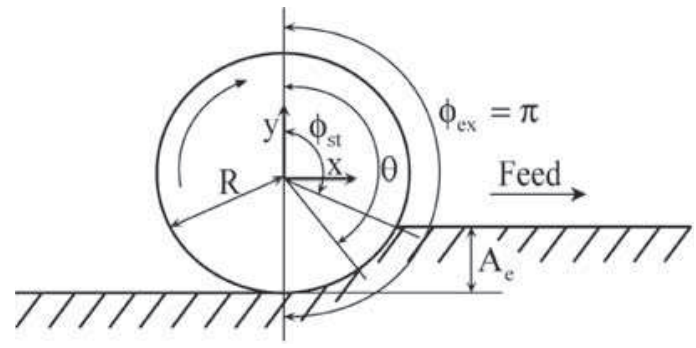

Fig. 3. Start and exit angle in down-milling

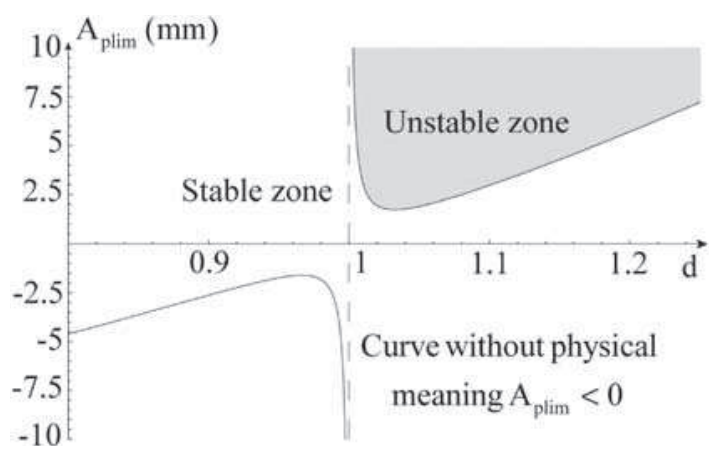

Fig. 4. $A_{\text {plim }}$ as a function of $d$

Table 1. Parameters used to plot Fig. 4

\begin{tabular}{ll}
\hline Steel plate $(\mathrm{S} 235)$ & $A_{e}=0.1 \mathrm{~mm}$ \\
$R=4 \mathrm{~mm}$ & $z=4$ \\
$K_{t}=2400 \mathrm{MPa}$ & $K_{r}=0.9$ \\
$k=45 \times 10^{9} \mathrm{~N} / \mathrm{m}$ & $\xi=0.033$ \\
$\omega_{0}=592 \mathrm{~Hz}$ & \\
\hline
\end{tabular}

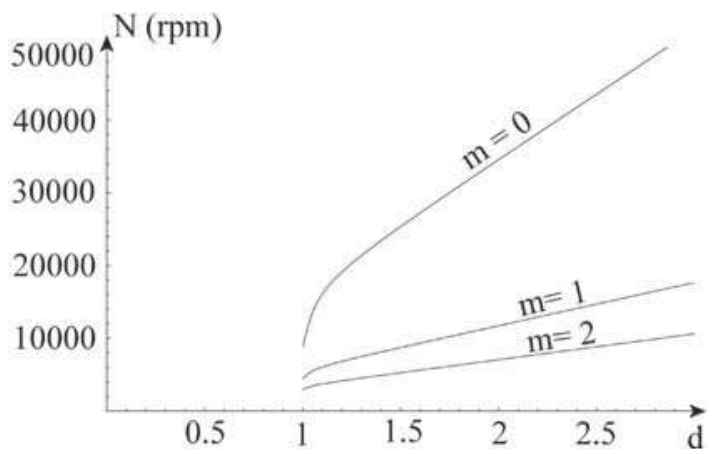

Fig. 5. $N$ as a function of $d$

2.4 Calculation of critical axial depth of cut according to the spindle speed and a whole number of vibration cycles

At this stage, we have $A_{\text {plim }}=f\left(\omega_{c}\right)$ and $N=f\left(\omega_{c}\right)$. The function $N=f\left(\omega_{c}\right)$ is not invertible analytically, so we adopt a parametric representation of the lobes, where $\omega_{c}$ is the parameter (Fig. 6). Each lobe represents the stability limit for a number of full vibration cycles $m$. The same parameters as in Figs. 4 and 5 are used.

This calculation is applicable to each natural mode of vibration of the workpiece, when they are non coupled. The workpiece

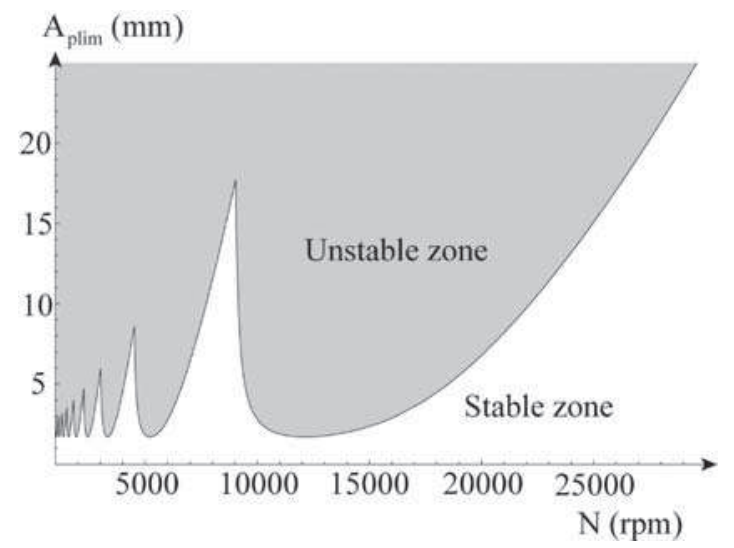

Fig. 6. Characteristic plot of stability lobes

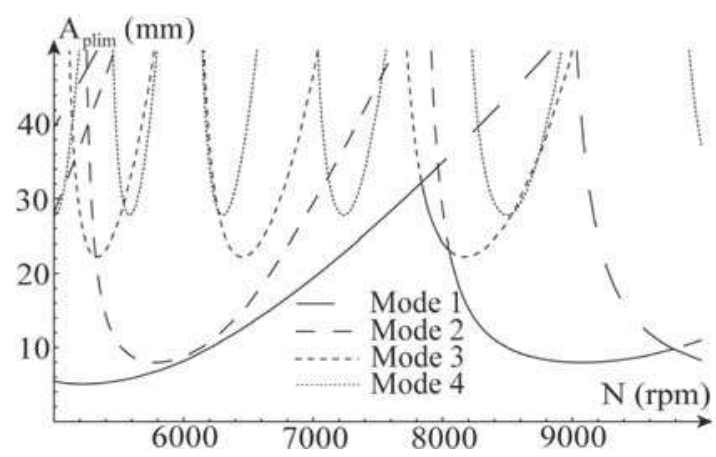

Fig. 7. Stability lobes for four modes 
Table 2. Modal properties of the workpiece and cutting conditions used to plot the graph in Fig. 7

\begin{tabular}{lrlc}
\hline Mode & $\omega_{0}(\mathrm{~Hz})$ & $\xi$ & $k(\mathrm{~N} / \mathrm{m})$ \\
\hline 1 & 592 & 0.033 & $44.497 \times 10^{9}$ \\
2 & 1088 & 0.023 & $108.109 \times 10^{9}$ \\
3 & 2100 & 0.01 & $803.759 \times 10^{9}$ \\
4 & 3320 & 0.009 & $1.119 \times 10^{12}$ \\
\hline Steel plate (S235) & \multicolumn{2}{c}{$R=4 \mathrm{~mm}$} & $z=4$ \\
$K_{t}=2400 \mathrm{MPa}$ & & $K_{r}=0.9$ & $A e=0.1 \mathrm{~mm}$ \\
\hline
\end{tabular}

has several number of significant natural modes of vibration. The stability limit is proportional to the modal stiffness and to the damping ratio Eqs. 2, 4. In Fig. 7, we can see that the limit fixed by the fourth mode is never reached.

\section{Obtaining model parameters}

The stability lobes calculation requires the dynamic parameters of the workpiece for each natural mode (natural frequency, damping ratio, stiffness). The stiffnesses are determined by a finite element calculation. The damping ratio cannot be easily calculated, so we determine it by measurement.

We use a laser vibrometer so as not to disturb the measurement, because there is no contact between the workpiece and the sensor. This sensor makes it possible to measure the natural frequencies on the milling machine, and by exciting the workpiece

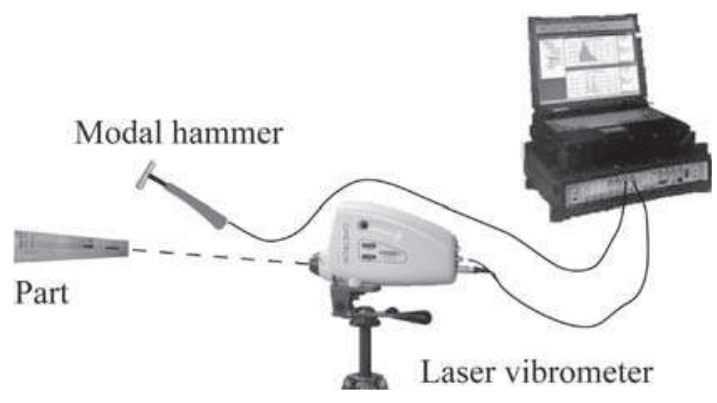

Fig. 8. Determination of dynamic parameters

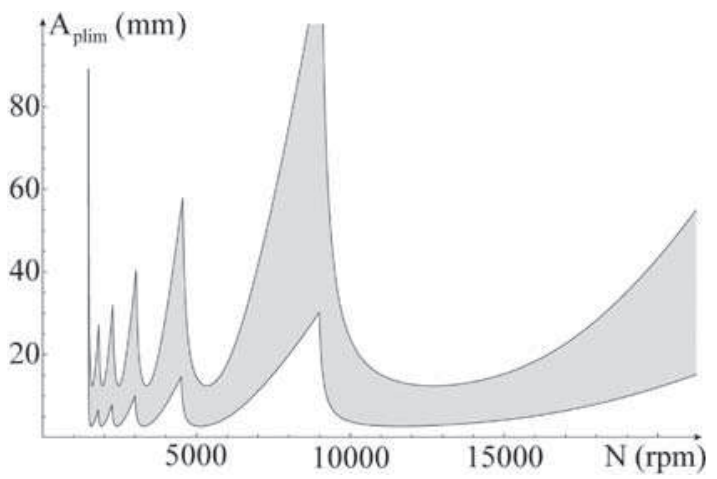

Fig. 9. Stability limit with tolerance margin due to measurement inaccuracy
Table 3. Parameters used to plot the graph in Fig. 9

$\omega_{0}=92 \pm 1 \mathrm{~Hz}$

$1134 \mathrm{MPa}<K_{t}<2880 \mathrm{MPa}$

$0.675<K_{r}<0.9$

$0.0297<\xi<0.0363$

$41.8 \times 10^{9} \mathrm{~N} / \mathrm{m}<k<46.2 \times 10^{9} \mathrm{~N} / \mathrm{m}$

$0.095 \mathrm{~mm}<A_{e}<0.105 \mathrm{~mm}$

with a modal hammer, we obtain the damping ratio (Fig. 8). This measurement also allows us to verify the accuracy of the stiffness calculation by comparing the measured frequencies and the calculated frequencies.

Given the measurements inaccuracy, we define the stability limit with a given tolerance margin. Thus, we obtain two curves between which the real stability limit of the system lies (see Fig. 9).

\section{Influence of the tool position on the dynamic behaviour of the workpiece}

When a thin-walled structure is machined, we can see that the machined surface is not homogeneous in terms of surface quality. We can see strongly perturbed and slightly perturbed zones (Fig. 14). Thus, the workpiece cannot be considered as a rigid body in the machined zone, and the dynamic behaviour of the workpiece depends on the position of the tool. We thus introduce a third dimension in the stability lobes diagram.

In the third dimension, we introduce the application point of the cutting force, which determines how each mode is excited. For example, the dynamic behaviour of a mode is very different if the exciting force is in a node or in a loop.

The initial dynamic equation used for the stability lobes calculation is:

$\ddot{U}+2 \xi \omega_{0} \dot{U}+\omega_{0}^{2} U=\left(\left(\underline{F}_{c} \cdot \underline{y}\right) \omega_{0}^{2}\right) / k$

The displacement $\underline{u}$ of a point $\underline{x}$ of the structure, represented by its $n$ first modes, is defined by:

$\underline{u}(\underline{x}, t)=\sum_{i}^{n} \underline{u}_{i}(\underline{x}, t)$

with

$\underline{u}_{i}(\underline{x}, t)=\alpha_{i}(t) \underline{\Phi}_{i}(\underline{x})$

where $\underline{\Phi}_{i}(\underline{x})$ is the modal displacement of the mode $i$, and $\alpha_{i}(t)$ is a time function.

The modal equation for each mode is:

$\ddot{\alpha}_{i}(t)+2 \xi_{i} \omega_{i} \dot{\alpha}_{i}(t)+\alpha_{i}(t) \omega_{i}^{2}=\frac{\int_{\partial \Omega} \underline{\Phi}_{i}(\underline{x}) \underline{f}(\underline{x}, t) d S}{\int_{\Omega} \rho \underline{\Phi}_{i}(\underline{x}) \underline{\Phi}_{i}(\underline{x}) d \Omega}$ 
where $\omega_{i}$ is the natural pulsation of the mode $i, f(\underline{x}, t)$ is the force field and $\int \rho \underline{\Phi}_{i}(\underline{x}) \underline{\Phi}_{i}(\underline{x}) d \Omega$ is the modal mass $m_{i}$.

In fact, $\underline{f}(\underline{x}, t)$ is comparable to a localized force in point $M(t)$, which is mobile along $\underline{x}_{1}$. It is the cutting force $F_{c}(t)$ (Fig. 10).

So in Eq. 9,

$\int_{\Omega} \underline{\Phi}_{i}(\underline{x}) \underline{f}(\underline{x}, t) d \Omega=\underline{\Phi}_{i}(M(t)) \underline{F}_{c}(t)$

When the modes are normalized in displacement at point $M_{0}$, $\Phi_{i}\left(M_{0}\right)=1$ and, with Eqs. 7 and 8:

$\underline{u}_{i}\left(M_{0}, t\right)=\alpha_{i}(t)=\frac{\underline{u}_{i}(M(t), t)}{\underline{\Phi}_{i}(M(t))}$

Therefore, by substitution into Eq. 9, we obtain in $M(t)$ :

$\underline{\ddot{u}}_{i}(M(t), t)+2 \xi_{i} \omega_{i} \underline{\dot{u}}_{i}(M(t), t)+\underline{u}_{i}(M(t), t) \omega_{i}^{2}=\frac{\Phi_{i}^{2}(M(t)) \underline{F}_{c}(t)}{m_{i}}$

Eq. 12 is similar to the Eq. 6, with:

$U=\underline{u}_{i}(M(t), t) \cdot \underline{x}_{2}$

$\xi=\xi_{i}$

$\omega_{0}=\omega_{i}$

$k=\frac{k_{i}}{\underline{\Phi}_{i}^{2}(M(t))}$

$k_{i}, \omega_{i}$ and $\Phi_{i}(M(t))$ are obtained with finite element calculus. Also, it can be obtained by measurement.

The regenerative model of vibration is valid for an established mode. So, the time necessary for a significant variation of $k_{i}$ must be much longer that the time necessary for the system to reach the established mode. The cutting tests show that the stability transition is very fast compared to the variation of $k$ (Eq. 16).

Thus, we can plot the stability lobes for each natural mode and at any point of the tool trajectory. For one mode, since the stability limit is proportional to the stiffness $k$ given in Eq. 4, the stability limit increases when the tool is at a node. The stiffness $k$ is theoretically infinite at a node (Eq. 16, Fig. 12). In short, it is much more difficult to excite a mode when the excitation force is near a node, so the stability limit is much higher.

\section{Validation tests}

We now consider the peripheral down-milling of a steel plate. Its thickness is $1 \mathrm{~mm}$; two perpendicular sides are embedded (Fig. 10). The programmed radial depth of cut is $0.1 \mathrm{~mm}$, and the feed rate is $0.05 \mathrm{~mm} /$ tooth. We use a cylindrical mill; the diameter is $8 \mathrm{~mm}$ with 4 teeth, and the helix angle is $45^{\circ}$.

The stability lobes of this workpiece are represented (Fig. 11) for the first and second modes. The same parameters as in Fig. 4
Fig. 10. Application point of the cutting force in the test workpiece
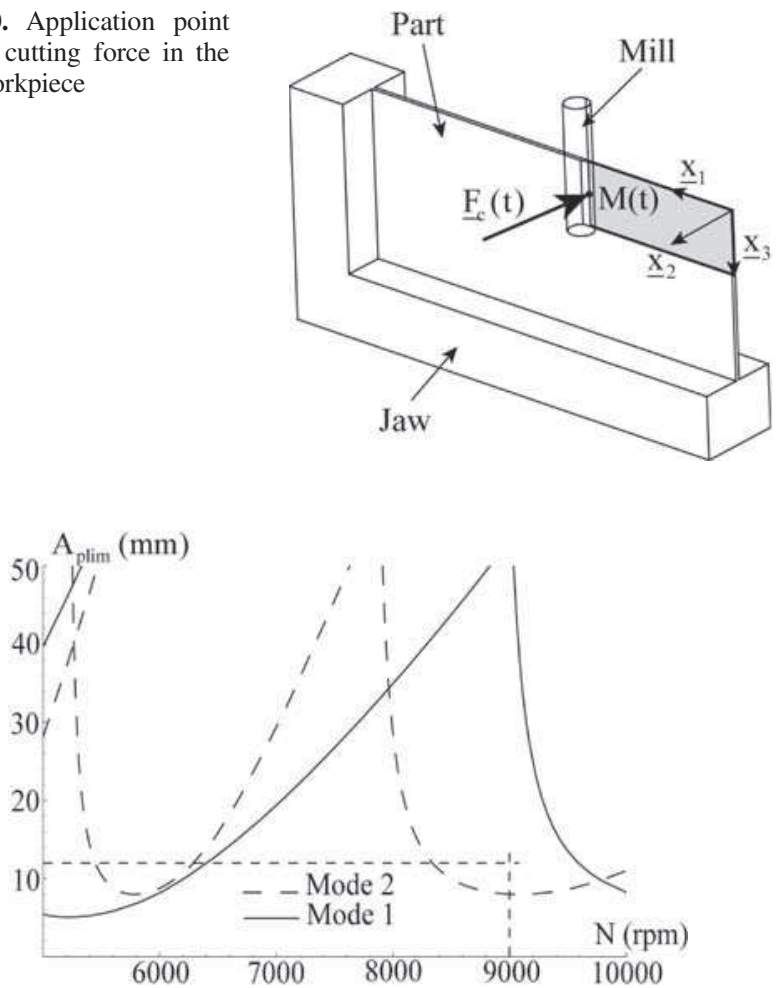

Fig. 11. Stability lobes for the first and second modes of the test workpiece

are used. It is plotted in point $M_{0}$ of the workpiece, which is the free corner.

A machining pass with a constant axial and radial depth of cut is realized. We voluntarily use an unstable spindle speed at point $M_{0}$ to excite the second mode of the workpiece, i.e. $N=9000 \mathrm{rpm}$ and $A_{p}=12 \mathrm{~mm}$. The stability lobes in three dimensions for the second mode of the workpiece are represented in Fig. 12.

With a section of the stability lobes in three dimensions in the plane $\left(x_{1}, A_{\text {plim }}\right)$ at $N=9000 \mathrm{rpm}$, we can determine where the vibrations will appear in the workpiece (Fig. 13). We also machined a workpiece while increasing the axial depth of cut to determine the stability limit as a function of location on the workpiece with the aim of readjusting the stability lobes along $A_{\text {plim. }}$.

We can see a good correlation between the position of the predicted stability transitions and those observed in the machined surface (Fig. 14).

Moreover, by comparing this surface with the modal deformation of the second mode given by finite element calculus (Fig. 14), we can see the nodes (zone 4) and the loops (zones 1 and 7) of the mode. On the other hand, we observe different transition zones in the surface.

The fourth zone is in the node of the mode, and we can see that the surface quality is relatively acceptable. In this zone, the machining is stable as predicted by the lobes.

The first and seventh zones are in the loops of the mode; the workpiece behaviour is strongly unstable and non-linear during 


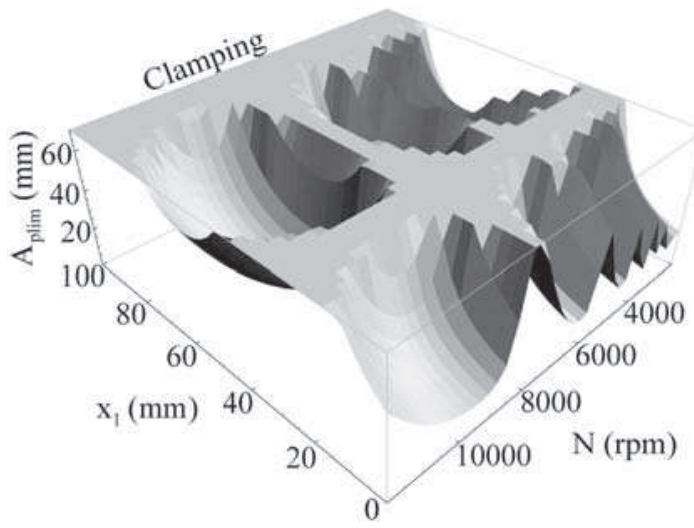

Fig. 12. Stability lobes in three dimensions for the second mode of the workpiece

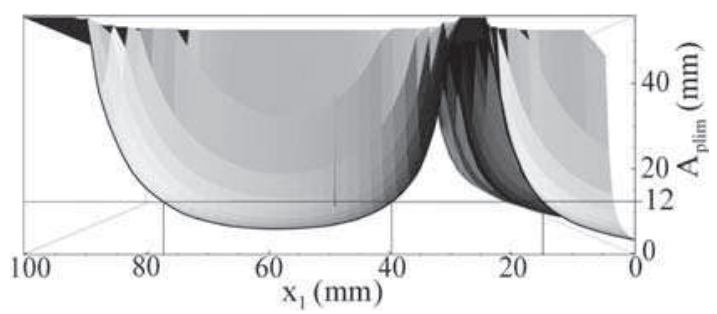

Fig. 13. Section at $N=9000 \mathrm{rpm}$ in the plane $\left(x_{1}, A_{\text {plim }}\right)$

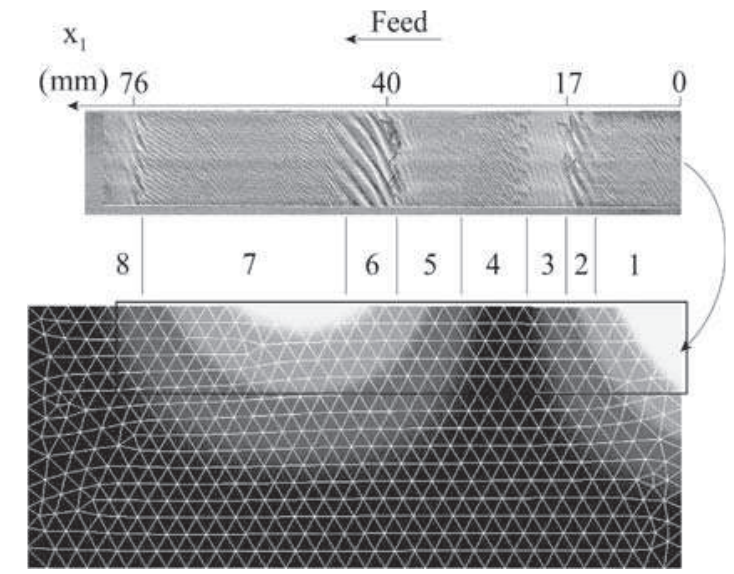

Fig. 14. Position of the stability transitions in the machined surface and correlation with the modal deformation of the second mode

machining, even if the surface quality seems acceptable. Therefore, it is very difficult to predict the workpiece behaviour, since the vibrations are so important that the tool doesn't remain in contact with the workpiece $[11,12]$.

The transition from unstable zone to stable zone (and conversely) is in two distinct stages. The first stage (second, sixth and eighth zones) presents a very poor surface quality where the marks show an attenuation of the vibration in term of amplitude and frequency compared to stable zones. These marks are well-ordered, firstly because the tool leaves the workpiece, and secondly because the vibration frequency tends to match with a multiple of the tooth frequency. The second stage (third and fifth zones) shows a softer behaviour of the workpiece. The vibration frequency is stable, and the tool does not leave the material. We observe only an attenuation (or increase) of the amplitude.

We will not pursue the study of the different marks observed in the machined surface, because the information given by them (amplitude and frequency) can be obtained by other methods, which will be discussed in the next section.

As stated earlier, the surface quality of the unstable zones can be compared to that observed in the stable zone, and is found to be even better than the surface quality of the stable zone. Nevertheless, in the unstable zones, it is very difficult to control the radial depth of cut and thus, the dimensional constraints. Moreover, the emergence of unstable zones necessarily goes through very perturbed transition zones around the modal nodes of the workpiece. These transition zones do not respect the constraints of surface quality, so we do not try to get some benefit from unstable zones.

\section{Measure of vibrations during machining}

To measure vibrations during machining, Delio et al. [13] suggest measuring the sound intensity, but this method requires attenuation filters which are not compatible with a workshop. Thus, it is very difficult to apply this method in these conditions. Therefore, the measuring circuit described earlier, used to determine the dynamic parameters of the workpiece, will allow us to measure the vibrations of the workpiece during machining. On the other hand, this measure is incompatible with the use of lubrication, since the beam is perturbed by the cutting fluid. Therefore, we have to carry out machining without lubrication to be able to measure the vibrations. From experience, we know that the cutting fluid slightly increases the damping ratio of the machining system. Thus, if a machining is stable without lubrication, it will be more stable with lubrication.

To measure the vibrations, we record the signal in the time domain during the machining thanks to signal processing software. The software allows us to select the part of the signal which corresponds to the zone under consideration and to display an FFT in order to obtain the different vibration frequencies of the workpiece in this zone. Thus we can characterize each zone in terms of frequency and amplitude.

\section{Discussion}

By definition, machining is a forming process by material removal. Therefore, when the material removal is significant, the dynamic properties (natural frequencies, mainly) of the workpiece change according to the tool position. Thus, we include the variation of the dynamic parameters of the workpiece in the third dimension of the stability lobes, on top of behaviour variation 
of the nodes and the loops. The variation of the natural frequencies of the workpiece during machining introduces a shift of the lobes along the spindle speed axis. Consequently, if this shift is rather significant, it is possible that no stable spindle speed exists throughout the machining process. Then, we must adjust the spindle speed during machining in order to achieve a stable behaviour of the workpiece.

At the beginning of this article, we assumed that the tool is much more rigid than the workpiece. In practice, this assumption may not be true, and the tool and the workpiece may be mobile. In this case, if the natural modes of the tool and the workpiece are close, there can be coupling between them. The stability lobes theory presented is no longer valid, and we have to rewrite the equations according to the new configuration.

We also assumed that the tool is cylindrical with a constant cutting speed at any point on its periphery, and with a constant helix angle. Thus, the distribution of the cutting force is uniform along the tool, and we know the resultant position of this distributed cutting force. A problem arises if we must use a tapered end-mill with a non constant helix angle. In this case, the distribution of the cutting force is no longer uniform, and the resultant position of the cutting force changes.

Also, we will use a deformable taper end mill to machine a thin-walled structure with a significant material removal (machining of a centrifugal impeller).

\section{Conclusion}

In this article, we show how to introduce in the stability lobes theory the dynamical behaviour variation of the workpiece with respect to tool position. A third dimension, the tool position, is introduced in the stability lobes diagram. This 3D lobes construction is validated by an experimental approach. Thus, we can obtain the optimal cutting conditions all through the machining process.
It is also necessary to integrate into the stability lobes model the variation of the dynamic parameters of the workpiece during machining due to material removal, and the use of a deformable tool. This work is in progress and will be developed further. The model thus obtained will have to be integrated with the CADCAM system, or developed with specific software adapted to an industrial context.

\section{References}

1. Tobias SA, Fishwick W (1958) A theory of regenerative chatter. Engineer, London

2. Tlusty J, Polacek M (1963) The stability of machine tools against self excited vibrations in machining. Int Res Prod Eng, pp 465-474

3. Merritt HE (1965) Theory of self-excited machine tool chatter. ASME J Eng Ind 87:447-454

4. Sridhar R, Hohn RE, Long GW (1968) General formulation of the milling process equation. ASME J Eng Ind, pp 317-324

5. Sridhar R, Hohn RE, Long GW (1968) A stability algorithm for the general milling process. ASME J Eng Ind, pp 330-334

6. Altintas Y, Budak E (1995) Analytical prediction of stability lobes in milling. Ann CIRP 44(1):357-362

7. Lapujoulade F, Mabrouki T, Raïssi K (2002) Prédiction du comportement vibratoire du fraisage latéral de finition des pièces à parois minces. Mécanique et Industrie 3(4):403-418

8. Davies MA, Balachandran B (2000) Impact dynamics in milling of thin walled structures. Nonlinear Dyn 22:375-392

9. Budak E, Altintas Y (1998) Analytical prediction of chatter stability in milling - part I: general formulation. Trans ASME 120:22-30

10. Budak E, Altintas Y (1998) Analytical prediction of chatter stability in milling - part II: application of the general formulation to common milling systems. Trans ASME 120:31-36

11. Fofana MS (2002) Effect of regenerative process on the sample stability of a multiple delay differential equation. Chaos Solitons Fractals 14:301-309

12. Minis I, Yanushevsky T, Tembo R, Hocken R (1990) Analysis of linear and nonlinear chatter in milling. Ann CIRP 39:459-462

13. Delio T, Smith S, Tlusty J (1992) Use of audio signals chatter detection and control. J Eng Ind 114:27-34 